\title{
Poverty Alleviation in Zang People's Regions of Yunnan Province from the Perspective of Accurate Anti-poverty
}

\author{
Xiaobo He \\ Yunnan University of Finance and Economics, Kunming, P.R China 650221 \\ hexiaobo921@hotmail.com
}

Keywords: Accurate poverty; Zang People's regions in Yunnan; Countermeasure research

\begin{abstract}
Poverty alleviation in Zang People's regions of Yunnan is one of the social events which has drawn so much attention from China's government, academics and social community. The following passage is formed in the impact of construction of well-to-do society fully in the 18th Congress of Communism Party and President Xi Jinping's investigation and speech in Yunnan province in 2015. It sets Diqing Zang People autonomous prefecture as an example, discovers and concludes the new problems and tendency in the transformation from old-fashion to accurate poverty alleviation. Then, appropriate suggestions are given to improve stability and development of economy and society for Zang people, which is beneficial to eliminate poverty fully.
\end{abstract}

\section{Introduction}

China's poverty issues mainly focus on minority ethnic group areas. According to the 6th national demographic census data, minority ethnic group population is made up of $8.41 \%$ of China's total population. However, the poverty population in rural areas of minority ethnic group regions is amount to $47.7 \%$ of total national poverty population ( 26.1 million). The occurrence rate of poverty is 5 percent point is higher than the national average level $(2.8 \%)$. At present, China has set 592 national-poverty level countries. Among them, 258 countries are in minority ethnic group areas. The number of national-poverty level countries distribution in West areas has been made up of $86.8 \%$ of total national-poverty level countries, $59.7 \%$ of total Western national-poverty level countries and 38.7 of total Western minority ethnic groups countries.[1]Most national-poverty level countries are distributed in the West as Sichuan, Guizhou, Yunnan, Gansu, Neimenggu and so on. Western poverty issues are equal to poverty events of minority ethnic groups.

Zang People's region is the national autonomous area for Zang people and other ethnic groups together, so it has its own traits of minority ethnic groups, region boundary and religion. For the poverty area of minority ethnic groups, Zang people's area has the difference in geographical location, ecological environment, demographic structure, religion, economic base and living styles, so the traits and issues for poverty alleviation in Zang people's regions ought to be different comparing with other poverty areas. It is helpful for the long stability and economic and social development to discover the rules for poverty alleviation in Zang people's regions. In the 14 national central interlink chains of extreme poverty areas, Diqing Zang People's autonomous prefecture in Yunnan is one of the areas with the biggest poverty area and the most serious poverty level. Art present, the per ca-pita disposable income for rural villagers in Diqing is $56.8 \%$ and $78.7 \%$ comparing with national average level and provincial average level.[2]It is significant in theory research and reality to do research in poverty alleviation in Zang people's area in Yunnan.

\section{The Connotation and Significance of Accurate Poverty Alleviation}

The Putting forward for Accurate Poverty Alleviation. China has enforced poverty alleviation since 2080s. Through 30 years' effort, China has gained outstanding achievements in poverty alleviation. However, some problems as unclear poverty people's exact number, average poverty station, indirect pertinence, unclear direction in poverty fund use have existed for a long time. One of the reasons to explain the above phenomena is the inaccurate poverty people. At present, China has the population of 82.49 million in poverty. The number is made by the evaluation of national 
74000 rural families. The number is not accurate and scientific for analyzing the national poverty level and poverty tendency. For this reason, the concept and development strategy of accurate poverty alleviation has been formed.

The conception and thoughts of accurate poverty alleviation was put forward by President Xi Jinping in the investigation in Hunan in November 2013. It includes the contents as matter-of-fact, adjust measures to local conditions, giving different guidance to different categories and accurate poverty alleviation.[3]In January of 2014, general office of the central committee set the model of top-level design in details. In March of 2014, President Xi Jinping explained the thoughts of accurate poverty alleviation again.[4] In January of 2015, President Xi Jinping chose Yunnan province as the first investigation spot in a new year. He held that it must be successful in the war fighting with poverty and must speed the development of economy and society in minority ethnic groups areas up. 5 months later, he came to Guizhou and strengthened that all poverty people must get rid off poverty till 2020 and provide the thoughts again: the essential for poverty alleviation is the accuracy. Accurate poverty alleviation has been a hot keyword from then till now.

The Connotation of Accurate Poverty Alleviation. Accurate poverty alleviation is the opposite of extensive poverty alleviation. It means a series of scientific and efficient procedures to enforce accurate recognition, accurate management toward different poverty environment, different poverty villagers station.

The improvement of accurate poverty alleviation, the strengthen of poverty aids are the essential need to remit poverty level and make common prosperity come true. And also it is a storming of heavily fortified positions to realize small-well-society and modernization construction. So how to be accurate poverty alleviation? At first, accurate recognition. It is the base for accurate poverty alleviation. By through the efficient and scientific procedures, the people who really belong to poverty engage can be recognized. For example, the survey of poverty level should be enforced in each poverty family. The poverty family and villagers should be set in a official record. A series of survey should be enforced as villagers' evaluation, register investigation, announcement, snap cheek and so on. Whatever which ways to recognize poverty level, it is elementary to carry democracy at the grassroots level to ensure poverty families recognition in public and fairness. What's more, accurate poverty alleviation aids. This is the key for accurate poverty alleviation. After the recognition for poverty families and villagers, the special person who is in charge of the family should be set. And he must set the accurate poverty alleviation aids based on the village's poverty level in order to ensure the effect of poverty alleviation aids. The exact measures include the following: insist and enforce the central policy, make " 6 kinds getting into village families' come true (infrastructure, support for industry, education training, reconstruction of old and dilapidated buildings in rural areas, support and afford the immigrant for ecology, help the poor in pair programming) make different policy toward different villagers' poverty level, fund toward the poor family, civil servant's support and help in pair with the poor. At last, accurate management. This is the ensure for poverty alleviation. Three measures of management should be enforced: information management for the rural villagers, fund used publicly and fairly, management for rights and obligations in poverty alleviation.

The Significance of Accurate Poverty Alleviation. Policy of accurate poverty alleviation is the important insurance to make small-well-society come true and realize Chinese Dream to be strong and developed for the whole country. The significance of poverty alleviation job aims at helping the poor to realize the great Chinese Dream. Deleting poverty, improving ordinary people's life, making all people in richness are the essential need for socialism. Without the construction of small-well-society in rural areas, especially for the poor people in undeveloped areas, the whole construction of small-well-society can not be come true. Consequently, we must on the road of accurate poverty alleviation firmly and make the poor confident on the road of poverty alleviation and rich. Only on this way, can the small-well-society be constructed fully and Chinese dream of becoming strong and developed come true. 


\section{The Current Station of Zang People's Poverty in Yunnan}

The Current Station of Zang People's Poverty in Yunnan. Diqing Zang people's autonomous prefecture means good luck and happiness in Zang people's language. It lies in Northwest of Yunnan province, living to the boundary of Yunnan, Xizang and Sichuan. Diqing's total area is 23870 square kilometers. It boasts Shangri-La City, Deqin county and Weixi Lisu people autonomous county, 29 towns and social community and 188 village committee. In 2015, the total population is 408 thousand. Among these, minority ethnic groups have the population of 307.9 thousand. The GNP is 16.15 Billion yuan. The general public budget of the local finance is 1.56 billion yuan. The expenditure is 11.05 billion yuan. The average GNP is 39495 yuan, and the average revenue is 3811 yuan. The per ca-pita disposable income for city dwellers is 27097 yuan. The per ca-pita disposable income for rural villagers is 6487 yuan. It is in the level of the 3rd, 3rd, 14th and 9th in the provincial ranking respectively. Diqing is one of the 14 central contiguous serious poverty areas determined by central government in Zang people's areas in Sichuan, Gansu, Qinhai and Yunnan. At present, Shangri-La city, Deqin county and Weixi Lisu people autonomous county all belong to national key counties for poverty alleviation. Diqing has 120 poverty villages, 964000 poverty families with poverty registration. The rate of poverty is $30.3 \%$ which is 17.6 higher than the average provincial poverty level [5].

The Enforcement and Effect of Poverty Alleviation in Zang People's Regions in Yunnan. Diqing's governments and Party committee in various levels conscientiously carry out central and provincial poverty alleviation and development decision, and have achieved many good effects. Firstly, the population of poverty people has been reduced rapidly. The population of rural poverty people has been reduced from 199.6 thousand in 2010 to 96.4 thousand in 2015. Secondly, the quality of living and farming has been improved obviously. Since entering the "Twelfth Five-Year Plan", the investment funds for poverty alleviation totally has been amount to 1.75 billion yuan, which has really done great effect to the transportation, water conservancy, building reconstruction and so on for the poor in undeveloped areas. Thirdly, the effect of industrial poverty alleviation has been improved clearly. Based on the resources, Diqing has developed vigorously plateau characteristic modern agriculture such as grapes, medical materials and son on. So the biological processing for the energy and agricultural product has developed the second industry and the tourism which has been the leading of the third industry. All of these measures are helpful for the income increasing of the poor in Zang people's district. Fourthly, governments have explored measures as site relocation of "down the mountain out of poverty". For the poor people living in poor condition as terrible ecological environment, rare natural resources, less potential of development, government has led them in environmental immigration project. From 2011 to 2015, the environmental immigration has been amount to 10000 . Fifthly, the social public affairs have been improved rapidly. Especially government has invested more in education in medical affairs in order to solve the problem of difficulty in entering into school and seeing doctors in hospital. Sixth, government has strengthen the power in poverty alleviation. For example, government has explored some strong and powerful enterprise to supply counterpart assistance in poverty alleviation such as Yunnan Baiyao Group, China Eastern Airlines Yunnan branch and Yunnan Coppeer Group and so on.

\section{The Main Problems and Reasons in Yunnan Zang People's Poverty Alleviation}

The Number of Power People is Still High. Although Diqing's poverty alleviation has been improved a lot, many problems still exist such as weak infrastructure, undeveloped social public service, high cost of production and living and difficulty in increasing income for rural villagers. By the end of 2015, Diqing still has 96400 rural people in poverty. Poverty incidence is amount to $30.3 \%$ which is in the second level from the bottom in Yunnan. Comparing with the national average level, its poverty level is still serious and urgent.

More Serious Poverty Level in Special Type Area. At present most rural people in poverty live in mountain area, remote mountainous area and ethnic minority areas. So living conditions and 
development conditions are so poor. The possession of resources and development capital is so short for the poor people. What's more, due to the frequent and serious natural disasters, many poverty alleviation project newly built usually have been destroyed by weather-strained with the storm or sunshine. So the station of poverty has been existed all the same.

Various Factors to Cause Poverty. The problem than rural villagers are in the cycle of sickness, natural disaster leading to poverty is still obvious and urgent. Some factors as engineering resettlement, land expropriation, ecological environment protection and resource explored are mixed in deed in some extent, which has aggravated the difficulty of poverty alleviation. For example, relocation program for poverty alleviation is typical in the problem. According to the national subsidy standard, each person has 6000 yuan subsidy and almost 25000 yuan for a family. However, it needs 10000 yuan to build a new house locally. The large investment makes people in one disaster after another, so the phenomenon of returning poverty is very serious.

Weak Agricultural Foundation. Diqing has the natural weather condition as high altitude, low temperature, slow growth of crops, few high quality agricultural products, slow adjustment of agricultural structure and undeveloped agricultural products processing, so it has the difficulty in the capacity of self accumulation and self development. Recently, based on the plateau natural scenery and rich minority cultures, Diqing has developed tourism vigorously. The tourism line as Shangri-La is very hot in Yunnan's tourism. The tourism brand made by Diqing government has been well-known. However, the traditional agricultural which is the leading industry is also weak.

Low Overall Quality for Rural Poverty People. Most Zang people in rural poverty area has low cultural quality. They are not open-minded and lack of techniques to be rich. The overall rural people in poverty is not young. Some families which have the unable are amount to $20 \%$ of the total family number. The poor people are almost engaging in traditional agricultural and part-time jobs. They have no techniques to develop themselves and be rich and they rely on the traditional agricultural too much.

\section{Optimization Measures in Poverty Alleviation for Zang People from the Perspective of Accurate Poverty Alleviation}

Clearing Objectives and Responsibility. To make the accurate poverty alleviation come true, it is essential to have clear objectives and responsibilities. At first, the amount of poor people must be clear and accurate. For accurate poverty alleviation, it's so important to make clear about amount of poverty people, poverty level, reason for poverty, needs of poverty alleviation and main problems to solve poverty. Based on the above information, the record and register for the poor people can be done well. Secondly, the measure for poverty alleviation must be in reality. Based on the former station and effect of poverty alleviation, government should change ways of poverty alleviation and integrate various power in poverty alleviation in perspective of accurate anti-poverty. At last, responsibilities should be distributed definitely to the person. County government is in charge of the procedures as poverty alleviation planning, responsibility, management, enforcement and so on. So the aim to get rid off poverty, funds, capital and responsibility should be enforced by the local government at first.

Making and Enforcing Scientific plan of Poverty Alleviation. Firstly, making a scientific plan of poverty alleviation should be the platform for county government to integrate all funds referring to rural villagers and rural industry. Secondly, government should regard the plan of poverty alleviation as a goal for rural villagers to get rid off poverty. According to the willingness and suggestions from the rural poor people, ordinary people to professional workers and government officers to make plan of poverty alleviation. In the course of making plan, governments should make various level anti-poverty plan by the unit of towns, villages. So the task of entering the plans can be carried out into each family. Thirdly, plan of poverty alleviation should be regarded as the ways to decompose and detail the task of poverty alleviation. Plan of poverty alleviation should contain the following contents as industry development, immigrant and job-hunting, education support, medical aid, ecological protection, social public service and elemental infrastructure construction in minority ethnic group poverty areas. 
Planning and Coordination. For one thing, all level governments and Chinese Communism Party Committee ought to play the good role in leading poverty alleviation tasks. So it is essential to do well in planning, coordination, organizing, finance invest, propagandizing and so on. For another, it must be make professional power industry and society poverty alleviation in an integration and coordination. In the course, market should play a key role in resources distribution and social poverty alleviation. Consequently, government is a leading role and other power as professional departments, market, industry society ordinary people and so on all have to contribute its power to poverty alleviation as an organic whole.

Changing Thoughts and Ideas. Accurate poverty alleviation does not mean accurate poverty aid. So the organic power for poor people to get rid off poverty station is changing thoughts and ideas. Intelligence is the essential for poverty alleviation. Thus, government has to invest more funds in education. In all factors leading poverty, thoughts and ideas are the most important ones, for they are the internal cause. Poverty alleviation measures are always external cause. Internal cause is played in the first place. If the outdated and over conservative ideas can be changed in the pace of time for the poor, the effect of poverty alleviation must be obvious and successful.

Supervision and Inspection for Poverty Alleviation Effect. Poverty alleviation should be regarded as one of the tasks in government's supervision and inspection. Various government ought to supervise tasks based on goals. In the course, the plan of deadline to get rid off poverty is arranged as a time table for various level governments to compare, enforce, supervise and inspect poverty alleviation. Meanwhile, effect of poverty alleviation should be supervised regularly. All departments not only government but also non-government organizations, legal department and individuals can be the important powers to supervise the enforcement and effect of poverty alleviation.

All in all, poverty alleviation is a system project with a long-time to enforce. Because the economic accumulation level, social production power, boundary location, various minority ethnic groups cultures, complicated religions and so on, Zang people's poverty alleviation has its own traits. Based on a sounded plan of getting rid off poverty, poverty alleviation needs all efforts from the whole society.

\section{References}

[1] G.G Ran, Rethinking about Anti-poverty in Zang Peoples’ Regions, [J] Financial Science, 2006 (2), in Chinese.

[2] Office of Yunnan Provincial Government, Report of Poverty Alleviation in Diqing Zang Peoples' Regions, [R] 6th November, 2016, in Chinese.

[3] What's the Most Worried about for President Xi Jinping? Chinese Economy Web, 22nd February, 2016, in Chinese.

[4] What's the Connotation and Significance of Accurate Poverty Alleviation in Xi Jinping's Thoughts? Chinese Economy Web, 4th August, 2015 February, in Chinese.

[5] Office of Yunnan Provincial Government, Report of Poverty Alleviation in Diqing Zang Peoples' Regions, [R] 6th November, 2016, in Chinese. 